\title{
Relation between pulmonary clearance and particle burden: a Michaelis-Menten-like kinetic model
}

\author{
Rong Chun Yu, Stephen M Rappaport
}

\begin{abstract}
Objectives-To test the validity of a Michaelis-Menten-like kinetic model of pulmonary clearance of insoluble dusts. Methods-Data were investigated from studies of pulmonary clearance in F344 rats exposed to antimony trioxide $\left(\mathrm{Sb}_{2} \mathrm{O}_{3}\right)$, photocopy test toner, polyvinyl chloride powder (PVC), and diesel exhaust particles. The Michaelis-Menten-like model was used to develop a relation in which the pulmonary clearance half time was a linear function of lung burden. After combining all data, linear regression techniques were applied to investigate the underlying relations. With the estimated intercepts and slopes, the MichaelisMenten-like kinetic parameters $k_{\max }$ (maximal clearance rate) and $m_{i}$ (a characteristic lung burden at which $k_{\max }$ is reduced by $50 \%$ ) were derived for the four dusts.
\end{abstract}

Results-The experimental data fit the linear regression very well $\left(R^{2}=0.989\right)$, suggesting that pulmonary clearance for the four dusts followed MichaelisMenten-like kinetics. Values of the intercept terms were not significantly different among the four dusts $(P=0.294)$, indicating that the intrinsic clearance rates of F344 rats were the same among the four experiments. The intrinsic clearance half time was estimated to be $\mathbf{7 7 \cdot 8}$ days, leading to an estimated $k_{\max }$ of $0.0089 \mathrm{day}^{-1}$. However, the slopes of the linear relations were significantly different among the four dusts $(P<0.001)$. Values of $m_{1}$ were ranked in the order of: $\mathrm{Sb}_{2} \mathrm{O}_{3}(0.69 \mathrm{mg})<$ photocopy test toner $(0.97 \mathrm{mg})<$ diesel exhaust $(2.49 \mathrm{mg}) \simeq$ PVC $(2.90 \mathrm{mg})$.

Conclusion-This study suggests that the Michaelis-Menten-like kinetic model reasonably describes the kinetic behavior of pulmonary clearance in F344 rats. The parameters $m_{1}$ can be used to differentiate the potency of a particular dust for impairing pulmonary clearance.

(Occup Environ Med 1996;53:567-572)

Keywords: pulmonary clearance; insoluble dusts; Michaelis-Menten kinetics

The clearance of particles deposited in the mammalian lung represents a vital mechanism against toxic effects associated with exposures to airborne dusts. ${ }^{1-3}$ For insoluble particles deposited in the alveolar region, the most prominent clearance pathway involves phagocytosis by alveolar macrophages followed by transport to the conducting airways for mucociliary removal. A very small portion of the particle mass is cleared by other pathways-namely, direct penetration of particles through the alveolar epithelial cells or migration of alveolar macrophages loaded with particles into the interstitium where they are either retained or transported to the lymphatic system.

It has been shown that an excessive lung burden retards pulmonary clearance in rats. Klosterkötter and Bünemann ${ }^{4}$ showed that the rate of pulmonary clearance was influenced by both the initial lung burden and the nature of the particular dust. Hatch and Gross ${ }^{5}$ pointed out that the rate of long term pulmonary clearance was inversely proportional to the lung burden. Middleton et $a l^{6}$ first suggested that, at higher doses, the rate of clearance of asbestos might become saturated. Studies involving amosite fibres, ${ }^{7}$ particles of diesel exhaust (DEP), ${ }^{8-11}$ photocopy test toner (PTT), ${ }^{12}{ }^{13}$ carbon black, ${ }^{14}{ }^{15}$ and antimony trioxide $\left(\mathrm{Sb}_{2} \mathrm{O}_{3}\right)^{16}$ have all shown increases in the half time $\left(T_{1}\right)$ of pulmonary clearance at increasing lung burdens.

Although there is general agreement that clearance rates are reduced at large lung burdens, the functional relation between clearance and burden has been a matter of conjecture. For example, work with $\mathrm{Sb}_{2} \mathrm{O}_{3}{ }^{16}$ suggested a linear function between $T_{t}$ and lung burden, although studies of diesel exhaust ${ }^{11}$ and crystalline silica ${ }^{13}$ indicated nonlinear relations. (Note that one study ${ }^{16}$ involved direct chemical measurement of lung burden but the other two studies ${ }^{113}$ used radioactive tracer particles to estimate clearance rates.) Morrow ${ }^{1718}$ noted that excessive burdens could virtually cause pulmonary clearance to end and speculated, ${ }^{19}$ therefore, that a superlinear (curving upward) relation must exist between $T_{t}$ and lung burden.

As well as suggesting that the rate of pulmonary clearance depended upon the burden and the type of dust, publications also showed evidence that, at low burdens, clearance rates were about the same in exposed and unexposed rats. This led to speculation that threshold burdens existed, below which the clearance behaviour could not be differentiated from that of unexposed animals. Table 1 summarises these studies, which suggest that the threshold lung burdens ranged between 0.2 and $3 \mathrm{mg} / \mathrm{rat}$, depending upon the particu- 
Table 1 Burden of particulate matter in rat lungs which imposed no detectable change in pulmonary clearance

\begin{tabular}{llll}
\hline Dust & Rats/sex & Burden $(m g)$ & Ref \\
\hline PTT & F344/M & $0 \cdot 31$ & 13 \\
PTT & F344/F & $0 \cdot 19$ & 13 \\
PTT & F344/M & $0 \cdot 25$ & 13 \\
PTT & F344/F & $0 \cdot 19$ & 13 \\
PTT & F344/M & $0 \cdot 33$ & 33 \\
PTT & F344/F & $0 \cdot 22$ & 33 \\
DEP & F344/M & $0 \cdot 5$ & 10 \\
DEP & F344/F and M & $0 \cdot 6^{\star}$ & 11 \\
PVC & F344/F & 0.56 & 12 \\
TiO $_{2}$ & F344/M & $2 \cdot 97^{\star}$ & 12 \\
TiO $_{2}$ & F344/F & $2 \cdot 17^{\star}$ & 12 \\
Amosite fibres $^{*}$ & Wistar/M & $0.8-1.5$ & 7 \\
\hline
\end{tabular}

^Maximal lung burdens produced by the experiment.

lar dust, and give some indication that values might be smaller for females than for males.

Taken together, the scientific literature points to a complex relation between lung burden and pulmonary clearance where: $(a)$ the clearance rate is about equal in exposed and unexposed animals at low levels of lung burden, $(b)$ the clearance rate is inversely related to burden at higher levels, and (c) the functional relation between clearance rate and burden is related to the particular dust. In attempting to reconcile these observations into cohesive models, investigators have relied upon complicated descriptions, usually containing multiple compartments, sometimes with non-linear terms, and often including a "sequestration compartment" to deal with some portion of the burden (transferred under overload conditions). These models have been applied to describe the clearance of photocopy test toner, ${ }^{20}$ carbon black, ${ }^{15} 20$ amosite asbestos, ${ }^{2122} \mathrm{TiO}_{2},{ }^{21} 23$ crystalline silica, ${ }^{2123}$ and diesel exhaust. ${ }^{8024-26}$ Unfortunately, such complex models have many parameters which must be estimated, and raise questions concerning the criteria of goodness of fit, the sensitivity and variability of parameter estimates, the uniqueness of model solutions, and the biological interpretation of the parameters.

An alternative form of non-linear model which has been widely applied in biological systems to describe saturable phenomena is the Michaelis-Menten relation of enzyme kinetics. ${ }^{27}$ As macrophage mediated processes show capacity limited kinetics, it is reasonable to speculate that a Michaelis-Menten-like model might well provide an appropriate description for pulmonary clearance. Biozzi et $a l^{28}$ found that clearance of carbon particles from the blood could be saturated at high doses due to limitations in rates of phagocytosis of the particles by the reticuloendothelial systems of the liver and spleen. Normann ${ }^{29}$ showed that a Michaelis-Menten-like equation could be used to describe the clearance of intravenously administered colloidal particles. Smith $^{30}{ }^{31}$ proposed a Michaelis-Menten-like kinetic expression for particle clearance mediated by alveolar macrophages, and Menzel et $a l^{32}$ showed that Michaelis-Menten-like kinetics could be used to describe the clearance of nickel chloride from the rat's lung. None the less, even though a Michaelis-Menten-like model for particle clearance mediated by alveolar macrophages makes intuitive sense, such a model has not been validated empirically in vivo for different dusts.

Here, we will extend application of a Michaelis-Menten-like model of pulmonary clearance to account for the dose-dependent behaviour of particle clearance from the rat lung. This non-linear model will be transformed into a linear relation between $T_{t}$ and lung burden, the fit of which will be evaluated with data from experimental studies involving diesel exhaust, ${ }^{9}$ PVC, ${ }^{12} \mathrm{Sb}_{2} \mathrm{O}_{3},{ }^{16}$ and photocopy test toner ${ }^{33}$ in the lungs of $\mathrm{F} 344$ rats. Note that we excluded from consideration those studies where pulmonary clearance was estimated on the basis of coadministration of radioactive tracer particles, because our analyses indicated that these tracers behaved differently from the dusts under investigation. We will report separately the basis for this finding that tracer particles are cleared at different rates from the dusts themselves.

\section{Materials and methods}

Published data from studies of dust overload in F344 rats were selected in which the animals were exposed to dusts by inhalation at various concentrations, according to particular regimens. ${ }^{9121633}$ Pulmonary clearance was found by measurement of the cleared dusts themselves-that is, without the use of tracer aerosols. Table 2 summarises the properties of the test dusts and the protocols of these studies. The clearance rate coefficients for diesel exhaust, photocopy test toner, and PVC were estimated by the authors of the original studies $^{91233}$ assuming a one compartment model for pulmonary clearance. Because procedures for estimation of $T_{t}$ were not reported by Newton et $a l^{16}$ in the study of $\mathrm{Sb}_{2} \mathrm{O}_{3}$, we estimated $T_{t}$ from their data by the procedure applied to photocopy fluid by Muhle et al. ${ }^{33}$

Table 2 Test dusts and protocols of inhalation experiments with F344 rats

\begin{tabular}{|c|c|c|c|c|c|c|c|}
\hline $\begin{array}{l}\text { Test } \\
\text { particle }\end{array}$ & $\begin{array}{l}M M A D \\
(G S D)\end{array}$ & $\begin{array}{l}\text { Density } \\
\left(\mathrm{g} / \mathrm{cm}^{3}\right)\end{array}$ & $\begin{array}{l}\text { Animals } \\
\text { Igroup }\end{array}$ & $\begin{array}{l}\text { Exposure } \\
\left(\mathrm{mg} / \mathrm{m}^{3}\right)\end{array}$ & $\begin{array}{l}\text { Exposure } \\
\text { regimen }\end{array}$ & $\begin{array}{l}\text { Measurement of } \\
\text { lung burden } \\
\text { after exposure }\end{array}$ & $\operatorname{Ref}$ \\
\hline $\mathrm{Sb}_{2} \mathrm{O}_{3}$ & $\begin{array}{l}3 \cdot 1-3 \cdot 8 \mu \mathrm{m} \\
(1 \cdot 7)\end{array}$ & $5 \cdot 2$ & $5 \mathrm{M}$ and $5 \mathrm{~F}$ & $\begin{array}{l}\text { S: } 0,25,1 \cdot 08 \text {, } \\
\text { and } 23 \cdot 46 \\
\text { C: } 0, \cdot 06, \cdot 51 \text {, } \\
\text { and } 4 \cdot 5\end{array}$ & $\begin{array}{l}S: 6 \mathrm{~h} / \mathrm{d}, 5 \mathrm{~d} / \mathrm{wk} \\
\text { for } 13 \mathrm{wk} \\
\text { C: } 6 \mathrm{~h} / \mathrm{d}, 5 \mathrm{~d} / \mathrm{wk} \\
\text { for } 52 \mathrm{wk}\end{array}$ & $\begin{array}{l}\text { S: } 1,3,9,18 \text {, } \\
\text { and } 27 \mathrm{wk} \\
\text { C: } 36 \text { and } \\
52 \text { wk }\end{array}$ & 16 \\
\hline PTT & $\begin{array}{l}4 \cdot 0 \mu \mathrm{m} \\
(1 \cdot 5)\end{array}$ & $1 \cdot 2$ & $8-9 \mathrm{M}$ or $\mathrm{F}$ & $0,1,4,16$, and 64 & $\begin{array}{l}6 \mathrm{~h} / \mathrm{d}, 5 \mathrm{~d} / \mathrm{wk} \text { for } \\
13 \mathrm{wk}\end{array}$ & $\begin{array}{l}1,25,50, \\
\text { and } 75 \text { day }\end{array}$ & 33 \\
\hline PVC & $\begin{array}{l}1 \cdot 3 \mu \mathrm{m} \\
(2 \cdot 1)\end{array}$ & $1 \cdot 3$ & $5-8 \mathrm{~F}$ & $\begin{array}{l}0,3 \cdot 3,8 \cdot 3 \text {, } \\
\text { and } 20 \cdot 2\end{array}$ & $\begin{array}{l}25 \mathrm{~h} / \mathrm{wk} \text { for } \\
30.5 \mathrm{wk}\end{array}$ & $\begin{array}{l}1,3 \text {, and } \\
5 \text { month }\end{array}$ & 12 \\
\hline DEP & $\begin{array}{l}0 \cdot 1-0 \cdot 2 \mu \mathrm{m} \\
(\mathrm{n} / \mathrm{a})\end{array}$ & $\sim 2^{\star}$ & $4 \mathrm{M}$ and $4 \mathrm{~F}$ & $\begin{array}{l}0,0 \cdot 15,0.94 \text {, } \\
\text { and } 4 \cdot 1\end{array}$ & $\begin{array}{l}7 \mathrm{~h} / \mathrm{d}, 5 \mathrm{~d} / \mathrm{wk} \text { for } \\
18 \mathrm{wk}\end{array}$ & $\begin{array}{l}1 \mathrm{~d} \text { and } 1,5,15 \text {, } \\
33 \text {, and } 52 \text { wk }\end{array}$ & 9 \\
\hline
\end{tabular}


Data for male and female rats had been combined to measure clearance rates in the studies of diesel exhaust ${ }^{9}$ and photocopy test toner, ${ }^{33}$ although the rates were reported for each sex separately in the study of $\mathrm{Sb}_{2} \mathrm{O}_{3} .{ }^{16}$ (Note that only female rats were used in the study of PVC. ${ }^{12}$ )

\section{A MICHAELIS-MENTEN-LIKE MODEL OF} PULMONARY CLEARANCE

Smith $^{31}$ proposed the following MichaelisMenten-like model for clearance of insoluble particles from the lung:

$$
k=\frac{k_{\max } \cdot m_{1}}{m_{1}+m}
$$

where $k$ is the coefficient for the rate of pulmonary clearance $\left(\right.$ day $\left.^{-1}\right), k_{\max }\left(\right.$ day $\left.^{-1}\right)$ is the constant for the maximal clearance rate, $m_{1}(\mathrm{mg})$ represents a characteristic lung burden at which $k_{\max }$ is reduced by half, and $m(\mathrm{mg})$ is the lung burden. Note that equation (1) presents $k$ as a non-linear function of burden $(m)$, which seems to be consistent with the empirical behaviour of pulmonary clearance found in rats. That is, at low burdens where $m \ll m_{1}, k$ is almost independent of $m$ - that is, $\left(k \cong k_{\max }\right)$ and at larger burdens $k$ decreases with $m$. Substitution of

$$
k=\frac{\ln (2)}{T_{\frac{1}{2}}}
$$

into equation (1) and rearrangement gives

$$
T_{\frac{1}{2}}=\frac{\ln (2)}{k_{\max }}+\frac{\ln (2)}{k_{\text {max }} \cdot m_{\frac{1}{2}}} \cdot m=\alpha+\beta \cdot m
$$
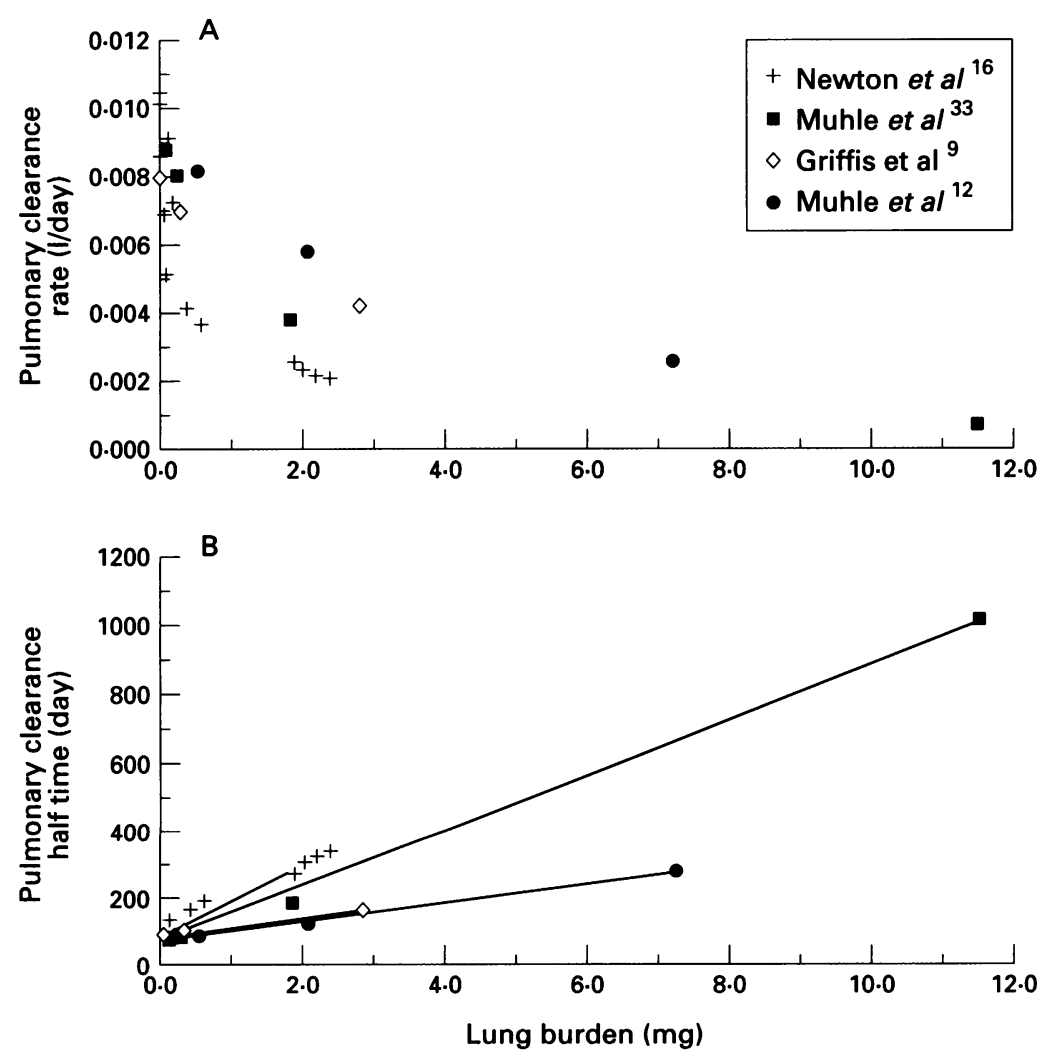

Relations between lung burden and either $(A)$ pulmonary clearance rate or $(B)$ clearance half time. The solid lines in (B) were obtained from linear regression models with coefficients reported in table 3. where $\alpha=\frac{\ln (2)}{k_{\max }}$ and $\beta=\frac{\ln (2)}{\left(k_{\max } \cdot m_{1}\right)}=\frac{\alpha}{m_{\frac{1}{2}}}$

The intercept $\alpha$ represents the intrinsic clearance half time (day) in the lungs of unexposed rats (when $m=0$ ). The slope $\beta$ (day/mg) represents the incremental loss of clearance (increase of $T_{1}$ ) imposed by one unit mass of lung burden. Clearly, a good fit of experimental data to the linear model described by equation (2) would suggest Michaelis-Menten-like kinetic behaviour consistent with equation (1).

\section{STATISTICAL ANALYSES}

Linear regression analyses, as suggested by equation (2), were used to analyse the experimental data of the four dusts by use of the GLM procedure of SAS (SAS Institute, Cary, NC). The regression equation can be expressed as:

$$
T_{\frac{1}{2}, i}=\alpha_{i}+\beta_{i} \mathrm{~m}_{i}+\varepsilon_{i}
$$

where the subscript $i=1,2,3,4$ refers to the $i$-th dust and $\varepsilon$ represents the error term. After estimating the coefficients $\alpha$ and $\beta$ for each dust, the test of a common intercept $H_{0}: \alpha=\alpha_{i}$ (all four dusts having the same intercept) versus $H_{1}: \alpha \neq \alpha_{i}$ (at least one dust having a separate intercept) was tested. Similarly, a test of common slope, $\beta$ versus $\beta_{i}$, was performed. Estimates of $k_{\max }$ and $m_{\frac{1}{2}}$ were derived from these coefficients through equation (2) based upon first order Taylor series approximations. ${ }^{34}$

\section{Results}

The figure depicts the empirical relations between lung burden and either $k$ (fig A) or $T_{\frac{1}{2}}$ (fig B) for the four dusts. From the figure (A) it is clear that the clearance rate coefficient, $k$, decreases exponentially with lung burden. Tables 3 and 4 show the linear regression analyses for the relations between lung burden and $T_{1}$ for the four dusts. The experimental data fit the linear model very well $\left(R^{2}=\right.$ $0 \cdot 989$ ), suggesting satisfactory descriptions of

Table 3 Results of linear regression analysis for parameter estimates (strength of the linear regression model $\left(R^{2}\right)=$ 0.989)

\begin{tabular}{llcl}
\hline Parameter & Test dust & Estimate $^{*}$ & $S E$ \\
\hline Intercept (day) $\alpha$ & All & $77 \cdot 8$ & $6 \cdot 0$ \\
Slope (day/mg) $\beta_{1}$ & $\mathrm{Sb}_{2} \mathrm{O}_{3}$ & $112 \cdot 1$ & $6 \cdot 1$ \\
Slope (day/mg) $\beta_{2}$ & $\mathrm{PTT}$ & $80 \cdot 3$ & $2 \cdot 0$ \\
Slope (day/mg) $\beta_{3}$ & $\mathrm{DEP}$ & $31 \cdot 2$ & $8 \cdot 2$ \\
Slope (day $/ \mathrm{mg}) \beta_{4}$ & $\mathrm{PVC}$ & $26 \cdot 9$ & $3 \cdot 1$ \\
\hline
\end{tabular}

*All estimates are significantly greater than zero $(P<0.05)$.

Table 4 Results of linear regression analysis to test hypotheses

\begin{tabular}{lr}
\hline Null hypothesis & Pvalue \\
\hline Common intercept $\left(\alpha_{1}=\alpha_{2}=\alpha_{3}=\alpha_{4}\right)$ & 0.294 \\
Common slope $\left(\beta_{1}=\beta_{2}=\beta_{3}=\beta_{4}\right)$ & $<0.001$ \\
$\beta_{1}=\beta_{2}$ & $<0.001$ \\
$\beta_{1}=\beta_{3}$ & $<0.001$ \\
$\beta_{1}=\beta_{4}$ & $<0.001$ \\
$\beta_{2}=\beta_{3}$ & $<0.001$ \\
$\beta_{2}=\beta_{4}$ & $<0.001$ \\
$\beta_{3}=\beta_{4}$ & 0.617 \\
\hline
\end{tabular}


Table 5 Estimate ${ }^{\star}$ of kinetic parameters $k_{\max }$ and $m_{1}$

\begin{tabular}{llllll}
\hline & \multicolumn{2}{l}{$k_{\max }\left(\right.$ day $\left.^{-1}\right)$} & & \multicolumn{2}{l}{$m_{1}(m g)$} \\
\cline { 2 - 3 } \cline { 5 - 6 } Test dust & Estimate & $S E$ & & Estimate & $S E$ \\
\hline $\mathrm{All}$ & 0.0089 & 0.0007 & & - & - \\
$\mathrm{Sb}_{2} \mathrm{O}_{3}$ & & & 0.69 & 0.08 \\
Photocopy test toner & & & 0.97 & 0.08 \\
Diesel exhaust & & & & 2.49 & 0.73 \\
PVC & & & & 2.90 & 0.46 \\
\hline
\end{tabular}

*Based on Taylor series approximations. ${ }^{34}$

the Michaelis-Menten-like kinetic behaviour. The test for a common intercept was not rejected $(P=0.294)$, indicating that the intrinsic rates of clearance of the four groups of animals were not significantly different, with an estimate of $T_{\frac{1}{2}}=77.8(\mathrm{SE}=6.0)$ days and an approximate $95 \%$ confidence interval $(95 \% \mathrm{CI})$ of $65 \cdot 3$ to $90 \cdot 3$ days.

The data depicted in the figure (B) did not satisfy the test for a common slope $(\beta, \mathrm{P}<$ 0.001 ), indicating that at least one of the $\beta$ s for the four dusts was significantly different from the others. Pairwise tests further showed that the $\beta$ for $\mathrm{Sb}_{2} \mathrm{O}_{3}(112 \cdot 1 \mathrm{day} / \mathrm{mg})$ was significantly greater than that for photocopy test toner $(80.3 \mathrm{day} / \mathrm{mg}, \mathrm{P}<0.001)$ and was also significantly greater than those for diesel exhaust $(31.2 \mathrm{day} / \mathrm{mg}, \mathbf{P}<0.001)$ and $P V C$ (26.9 day/mg, $\mathrm{P}<0.001)$. Values of $\beta$ for both diesel exhaust and PVC were significantly smaller than that for photocopy test toner $(\mathbf{P}<$ 0.001 ); however, the $\beta$ s for diesel exhaust and PVC were not significantly different from each other $(P=0.617)$. Thus, the estimated values of the $\beta$ s decreased in the order: $\mathrm{Sb}_{2} \mathrm{O}_{3}>$ photocopy test toner $>$ diesel exhaust $\cong \mathrm{PVC}$, suggesting a relative measure of the potency of the dust for impairing clearance mediated by alveolar macrophages.

To find whether the clearance behaviour of male and female rats was different, a separate analysis was performed for the data of $\mathrm{Sb}_{2} \mathrm{O}_{3}{ }^{16}$ which the authors had differentiated by sex. No significant differences were detected between male and female rats for either the intercepts $(P=0.378)$ or the slopes $(P=$ $0.523)$ of the linear relations. This suggests that the clearance behaviour was the same for male and female F344 rats.

With the estimated slopes and intercepts from table 3, we estimated the corresponding parameters for the Michaelis-Menten-like relation in equation (1) (table 5). The estimate of the intrinsic rate of clearance $k_{\max }$ (common to all dusts) was found to be 0.0089 (SE 0.0007) day $^{-1}$, whereas the estimated values of $m_{1}$ increased in the order: $\mathrm{Sb}_{2} \mathrm{O}_{3}$ $(0.69 \mathrm{mg})<$ photocopy test toner $(0.97 \mathrm{mg})$ $<$ diesel exhaust $(2.49 \mathrm{mg}) \cong$ PVC $(2.90 \mathrm{mg})$.

\section{Discussion}

This study provides evidence that the Michaelis-Menten-like relation given in equation (1) between rate of pulmonary clearance and particle burden is valid in F344 rats, at least for the dusts and experimental protocols which were available from the scientific literature. This depiction of pulmonary clearance is more parsimonious than earlier treatments (complex multicompartmental models with many parameters and often containing both linear and non-linear terms) because it contains only two parameters, and these can be easily estimated from relatively small amounts of experimental data by straightforward methods of regression analysis. We also note that model fit, which is problematic in situations involving complex models with many paramaters, is easily accomplished through residual analysis of the linear relation in equation (2).

Our Michaelis-Menten-like model relates to total alveolar clearance, which is mediated largely by alveolar macrophages, primarily through migration of particle laden cells to the ciliated airways, and to a minor extent through penetration of these cells through the interstitium to the pulmonary lymphatic system. Thus, the biological plausibility of this model draws upon analogies between the factors involving clearance mediated by alveolar macrophages and those of traditional Michaelis-Menten processes of enzyme kinetics. Enzymatic processes consist of at least two separate stages, one for joining a substrate (S) and enzyme (E) to form a complex (ES) and another for generating a product $(\mathrm{P})$ and recycling $\mathrm{E}$. The key to saturable MichaelisMenten kinetics is the fact that, as well as producing $\mathrm{P}$, the complex ES can also dissociate to release $E$ and $S$. So there is an inherent feedback system whereby some ES dissociates to regenerate $S$ rather than to entirely produce $\mathrm{P}$; and because this dissociation depends upon the concentration of ES, the overall process is saturable. In the pulmonary compartment of the lung, alveolar macrophages are analogous to $E$, free particles to $S$, phagocytised particles to $E S$, and cleared particles to $P$ (note that the clearance pathway, to either the ciliated airways or the lymph, is irrelevant as long as the clearance involves alveolar macrophages). The key element of feedback is realised through redistribution of the burden by which phagocytised particles can re-enter the alveolar space (after disruption of the alveolar macrophages), only to be phagocytised anew by other alveolar macrophages. ${ }^{235182035-45}$ Such release of phagocytised particles occurs not only because of the normal death of alveolar macrophages, but also due to factors related to particle loads in alveolar macrophages ${ }^{35} 37$ or to cytotoxicity of the particles. ${ }^{3546}$

In traditional Michaelis-Menten kinetics, the enzyme is not consumed by the process but, rather, is recycled to catalyse additional reactions. Clearly, particle laden alveolar macrophages cannot be recycled in the same manner. However, the population of alveolar macrophages is dynamic, young cells being continuously supplied by migration of monocytes from peripheral blood, interstitial macrophages, and local proliferation of resident macrophages (reviewed by Lehnert ${ }^{3}$ ). Older cells either migrate out of the non-ciliated space or die within the lung, ${ }^{35}$ and additional cells are recruited due to release of chemotactic factors associated with deposited 
particles. ${ }^{47} 48$ Because the number and capacity of alveolar macrophages at any time is ultimately limited, pseudo first order clearance is only possible up to some burden and beyond this point the kinetic processes responsible for clearance by alveolar macrophages became increasingly impaired, again in a manner analogous to enzymatic processes. That is, from equation (1) the rate of pseudo first order clearance, where $k \cong k_{\max }$, is the intrinsic clearance rate defined by the situation where $m \ll m_{1}$.

Estimates of the intrinsic pulmonary clearance of particles, represented either by $\alpha=$ 77.8 (SE 6.0) day (table 3) or by $k_{\max }=$ 0.0089 (SE 0.0007) day $^{-1}$ (table 5), are consistent with the values reported in the scientific literature. Ferin ${ }^{49}$ found that the long term clearance of dusts from rats receiving small burdens of $\mathrm{TiO}_{2}(<0.25 \mathrm{mg}$ per rat) was 88 days. Wolff et al ${ }^{11}$ reported the long term clearance $T_{1}$ for a group of unexposed rats to be 79 (SE 5) days. The relation between rate of alveolar clearance and lung burden of diesel exhaust, proposed by Yu and Yoon, ${ }^{26}$ gave an estimate of a maximal clearance rate of 0.0129 day ${ }^{-1}$ when there was no burden in the alveolar region. The multicompartmental model of Stöber et $a l^{20}$ gave estimates for the maximal rate of clearance mediated by alveolar macrophages of 0.013-0.015 day ${ }^{-1}$.

In contrast to suggesting that $k_{\max }$ was relatively uniform among the four studies that we investigated, our analyses pointed to significant differences in the parameter $m_{1}$ (the burden at which clearance is half of $k_{\max }$ ) among the dusts; where the estimates increased in the order: $\mathrm{Sb}_{2} \mathrm{O}_{3}(0.69 \mathrm{mg})<$ photocopy test toner $(0.97 \mathrm{mg})<$ diesel exhaust $(2.49 \mathrm{mg}) \cong$ PVC $(2.90 \mathrm{mg})$. This suggests that the dusts differed in their abilities to impair alveolar macrophages, either because of their physicochemical properties, their particle volumes, or both. Thus, we see that the parameter $m_{\frac{1}{2}}$ can be used to establish the range of pseudo first order kinetics (for $m \ll m_{1}$ ). Also, $m_{1}$ (or the corresponding value of the slope term $\beta$ when $\alpha$ is constant) provides a measure of the potency of a particular dust in impairing pulmonary clearance. Although our data suggest about a fourfold range of $m_{\frac{1}{1}}$ for these dusts, we anticipate that the range over many dusts would probably be substantially greater, particularly in so far as certain dusts-for example, crystalline silica, are well known to be cytotoxic to alveolar macrophages.

In studies of diesel exhaust Strom and coworkers fitted a six compartment kinetic model to experimental data obtained from F344 rats. ${ }^{24} 50$ The model included compartments for both phagocytic alveolar macrophages (designated as $\mathbf{M}$ ) and sequestered (particle laden) alveolar macrophages (designated as $S$ ). The authors used two parameters, $k_{m}$ and $k_{s}$, to characterise the non-linear behaviour of the $M$ and $S$ compartments, respectively. Interestingly, in each case the parameter was defined as the particle burden at which the respective clearance rate was half the maximal rate in either the $\mathrm{M}$ or $\mathrm{S}$ compartment. Thus, we would expect the sum of $k_{m}$ and $k_{s}$, from these studies of diesel exhaust by Strom and coworkers $^{2150}$ to be similar to our estimate of $m_{1}=2.49 \mathrm{mg}$ for diesel exhaust (table 5), which was based upon the data of Griffis et al. ${ }^{9}$ In the first experiment, ${ }^{24}$ where animals were exposed to intensive concentrations of diesel exhaust for up to 12 weeks, $k_{m}$ and $k_{s}$ were estimated to be 1.08 and $1.85 \mathrm{mg}$, respectively, from which $k_{m}+k_{s}=2.93 \mathrm{mg}$. In the second experiment, ${ }^{50}$ animals were exposed to low concentrations of diesel exhaust; in this case, the authors concluded that the sequestration (S) compartment was not needed and reported only a value of $k_{m}=3.40 \mathrm{mg}$. Both of these estimates $(2.93 \mathrm{mg}$ and $3.40 \mathrm{mg})$ lie within the approximate $95 \%$ CI of our $m_{\frac{1}{2}}$ for diesel exhaust (point estimate $=2.49 \mathrm{mg}$ ), which covers the range between 1.06 and 3.90 mg.

We anticipate that the kinetic parameter $m$ (or the slope term $\beta$ ) could be a meaningful index for pulmonary responses which are related to the ability of a dust to impair clearance. For example, in reviewing the mechanisms by which insoluble dusts produce lung tumours in rats, $\mathrm{Hext}^{45}$ hypothesised that impairment of normal alveolar clearance, either by overloading of the normal clearance mediated by alveolar macrophages with relatively inert particles-for example, $\mathrm{TiO}_{2}$ - or by induction of inflammation with more cytotoxic dusts - for example, crystalline silicarepresented a critical step in tumorigenesis. If this speculation is correct, then we would expect the parameter $m_{i}$ (or $\beta$ ) to be a useful measure of tumorigenesis.

Our finding of dust specific differences in the inhibition of pulmonary clearance can be used to estimate the threshold burden of each of the four dusts which would be required to experimentally differentiate clearance rates between exposed and unexposed rats. Based upon the estimated values of $k_{\max }$ and $m_{\frac{1}{2}}$ in table 5 and assuming that a significant increase in $T_{\frac{1}{1}}$ above the intrinsic value could only be detected at burdens above the upper limit of the approximate $95 \% \mathrm{CI}$-that is, 90.3 days-lung burdens of greater than $0 \cdot 11,0 \cdot 16$, 0.40 , and $0.46 \mathrm{mg}$ would be required for the test dusts of $\mathrm{Sb}_{2} \mathrm{O}_{3}$, photocopy test toner, diesel exhaust, and PVC, respectively, to observe significant retardation of clearance. These estimates are consistent with the range of values reported in the literature and summarised in table 1 .

Assuming that the size of the pool of alveolar macrophages in an F344 rat is $2.5 \times 10^{7}$ cells/lung, ${ }^{17}$ the mean phagocytosed mass for individual alveolar macrophages, associated with the estimated threshold burden of 0.11 mg for $\mathrm{Sb}_{2} \mathrm{O}_{3}$ (density $=5 \cdot 2 \mathrm{~g} / \mathrm{cm}^{3}$, table 2) would be $4.4 \times 10^{-6} \mu \mathrm{g} /$ alveolar macrophage, which is equivalent to $0.9 \mu \mathrm{m}^{3} /$ alveolar macrophage in terms of the corresponding volumetric capacity. Similarly, the average volumetric capacities for photocopy test toner, diesel exhaust, and PVC were estimated to be $5 \cdot 3,8 \cdot 0$, and $14 \cdot 2 \mu \mathrm{m}^{3} /$ alveolar macrophage, respectively. These values are considerably 
smaller than the range of $25-90 \mu \mathrm{m}^{3} /$ alveolar macrophage which was suggested by Morrow. ${ }^{18}$

Although we regard the finding of Michaelis-Menten-like clearance behaviour of the four dusts in this investigation as promising, we recognise that additional experimental confirmation will be required before the results can be generalised. Thus, we encourage other investigators to test the fit of their data to the linearised relation given in equation (2). We also recognise that extrapolation of the kinetic parameters $k_{\max }$ and $m_{1}$ to the human lung will be an important challenge for future research.

1 Schlesinger RB. Clearance from the respiratory tract. Fundam Appl Toxicol 1985;5:435-50.

2 Oberdörster G. Lung clearance of inhaled insoluble and soluble particles. F Aerosol Med 1988;1:289-330.

3 Lehnert BE. Pulmonary and thoracic macrophage subpopulations and clearance of particles from the lung. Environ Health Perspect 1992;97:17-46.

4 Klosterkötter W, Bünemann G. Animal experiments on the elimination of inhaled dusts. In: Davies CN, ed. Inhaled particles and vapors. New York: Pergamon Press. 1961: particles

5 Hatch TK, Gross P. Pulmonary deposition and retention of inhaled aerosols. New York: Academic Press, 1964.

6 Middleton AP, Beckett ST, Davis JMG. A study of the short-term retention and clearance of inhaled asbestos by rats, using UICC standard reference samples. In: Walton WH, ed. Inhaled particles IV, part I. Oxford: Pergamon Press, 1977:247-58.

7 Bolton RE, Vincent JH, Jones AD, Addison J, Beckett ST An overload hypothesis for pulmonary clearance of UICC amosite fibres inhaled by rats. Br $₹$ Ind Med 1983;40:264-72.

8 Vostal JJ, Schreck RM, Lee PS, Chan TL, Soderholm SC. Deposition and clearance of diesel particles from the lung. In: Lewtas J, ed. Toxicological effects of emissions from diesel engines. New York: Elsevier, 1982:143-59.

9 Griffis LC, Wolff RK, Henderson RF, Griffith WC, Mokle BV, McClellan RO. Clearance of diesel soot particles from rat lung after a subchronic diesel exhaust exposure. Fundam Appl Toxicol 1983;3:99-103.

10 Chan TL, Lee PS, Hering WE. Pulmonary retention of inhaled diesel particles after prolonged exposures to diesel exhaust. Fundam Appl Toxicol 1984;4:624-31.

11 Wolff RK, Henderson RF, Snipes MB, Griffith WC, Mauderly JL, Cuddihy RG, et al. Alterations in particle accumulation and clearance in lungs of rats chronically exposed to diesel exhaust. Fundam Appl Toxicol 1987;9: exposed

12 Muhle $H$, Creutzenberg $O$, Bellmann B, Heinrich $U$, Mermelstein R. Dust overloading of lungs: investigation of various materials, species differences, and irreversibility of effects. $\mathcal{F}$ Aerosol Med 1990;3(suppl 1):S111-28.

13 Bellmann B, Muhle H, Creutzenberg O, Dasenbrock C, Kilpper R, MacKenzie JC, et al. Lung clearance and retention of toner, utilizing a tracer technique, during chronic inhalation exposure in rats. Fundam Appl Toxicol 1991;17:300-13.

14 Lee PS, Gorski RA, Hering WE, Chan TL. Lung clearance of inhaled particles after exposure to carbon black gener-
ated from a resuspension system. Environ Res 1987;43: ated from

15 Strom KA, Johnson JT, Chan TL. Retention and clearance of inhaled submicron carbon black particles. $f$ Toxicol Environ Health 1989;26:183-202.

16 Newton PE, Bolte HF, Daly IW, Pillsbury BD, Terrill JB, Drew RT, et al. Subchronic and chronic inhalation toxicity of antimony trioxide in the rat. Fundam Appl Toxicol 1994;22:561-76.

17 Morrow PE. Possible mechanisms to explain dust overloading of the lungs. Fundam Appl Toxicol 1988;10: 369-84.

18 Morrow PE. Dust overloading of the lungs: update and appraisal. Toxicol Appl Pharmacol 1992;113:1-12.

19 Morrow PE, Mermelstein R. Chronic inhalation toxicity studies: protocols and pitfalls. In: Mohr U, et al, ed. Inhalation toxicology. New York: Springer-Verlag. 1988: 103-17.

20 Stöber W, Morrow PE, Morawietz G. Alveolar retention and clearance of insoluble particles in rats simulated by a new physiology-oriented compartmental kinetics model. Fundam Appl Toxicol 1990;15:329-49.

21 Vincent JH, Jones AD, Johnston AM, McMillan C, Bolton RE, Cowie $H$. Accumulation of inhaled mineral dust in the lung and associated lymph nodes: implications for exposure and dose in occupational lung disease. Ann Occup Hyg 1987;31:375-93.
22 Vincent JH, Johnston AM, Jones AD, Bolton RE, Addison J. Kinetics of deposition and clearance of inhaled minera dusts during chronic exposure. $B r \mathcal{F}$ Ind Med 1985;42: dusts durin.

23 Vincent JH, Donaldson K. A dosimetric approach for relating the biological response of the lung to the accumulation of inhaled mineral dust. Br F Ind Med 1990;47 302-7.

24 Strom KA, Chan TL, Johnson JT. Pulmonary retention of inhaled submicron particles in rats: diesel exhaust exposures and lung retention model. Ann Occup Hyg 1988; 32(suppl 1):645-57.

25 Yu CP, Morrow PE, Chan TL, Strom KA, Yoon KJ. A nonlinear model of alveolar clearance of insoluble particles from the lung. Inhalation Toxicology 1988;1: cles from

$26 \mathrm{Yu}$ CP, Yoon KJ, Chen JK. Retention modeling of diesel exhaust particles in rats and humans. $f$ Aerosol Med 1991 , 4:79-115

27 Voet D, Voet JG. Rates of enzymatic reactions. In Biochemistry. New York: John Wiley 1990:335-40.

28 Biozzi G, Benacerraf G, Halpern BN. Quantitative study of the granulopectic activity of the reticulo-endothelial system II. Br f Exp Pathol 1953;34:441-57.

29 Normann SJ. Kinetics of phagocytosis II. Analysis of in vivo clearance with demonstration of competitive inhibition between similar and dissimilar foreign particles. $L a b$ Invest 1974;31:161-9.

30 Smith TJ. Development and application of a model for estimation of alveolar and interstitial dust levels. Ann Occup Hyg 1985;29:495-516.

31 Smith TJ. Occupational exposure and dose over time: limitations of cumulative exposure. Am f Ind Med 1992 21:35-51

32 Menzel DB, Wolpert RL, Shoaf CR, Deal DL. Predicting human lung burdens of soluble nickel salts. In: Lee SD Schneider T, Grant LD, Verkerk PJ, eds. Aerosols: research, risk assessment, and control strategies. Chelsea, MI Lewis, 1986:637-48.

33 Muhle H, Bellmann B, Creutzenberg O, Fuhst R, Koch W, Mohr U, et al. Subchronic inhalation study of toner in rats. Inhalation Toxicology 1990;2:341-60.

34 Casella G, Berger RL. Point estimation-Taylor series approximations. In: Statistical inference. Pacific Grove, approximations. In: Statistical inference. Pacific

35 Lehnert BE, Valdez YE, Tietjen GL. AM-particle relationships during lung clearance. Am $\mathcal{F}$ Respir Cell Mol Biol 1989;1:145-54.

36 Lehnert BE, Toevs KE, Sebring RJ, Valdez YE. Failure of a simple model of AM-mediated particle clearance depict particle-AM relationships during early alveolar phase clearance. $₹$ Aerosol Med 1991;4:41-56.

37 Lehnert BE. Alveolar macrophages in a particle "overload" condition. F Aerosol Med 1990;3(suppl 1):S9-30.

38 Heppleston AG. The disposal of coal and haematite dusts inhaled successively. Fournal of Pathology and Bacteriology 1958;75:113-26.

39 Snipes MB. Long-term retention and clearance of particles inhaled by mammalian species. Crit Rev Toxicol 1989;20: 175-211.

40 Katsnelson BA, Konysheva KL, Sharapova NY, Privalova LI. Prediction of the comparative intensity of pneumoconiotic changes caused by chronic inhalation exposure to dusts of different cytotoxicity by means of a mathematical model. Occup Environ Med 1994;51:173-80.

41 Absher MP, Hemenway DR, Leslie KO, Trombley L, Vacek PM. Intrathoracic distribution and transport of aerosolized silica in the rat. Exp Lung Res 1992;18: 743-57.

42 Vacek PM, Hemenway DR, Absher MP, Goodwin GD The translocation of inhaled silicon dioxide: an empirically derived compartmental model. Fundam Appl Toxicol cally derived com

43 Hemenway DR, Absher MP, Trombley L, Vacek PM Comparative clearance of quartz and cristobalite from the lung. Am Ind Hyg Assoc $\mathcal{F}$ 1990;51:363-9.

44 Saffiotti U, Stinson SF. Lung cancer induction by crystalline silica: relations to granulomatous reactions and host factors. Environmental Carcinogens Reviews 1988;C6: 197-222.

45 Hext PM. Current perspectives on particulate induced pulmonary tumors. Hum Exp Toxicol 1994;13:700-15.

46 Brody AR, Roe MW, Evans JN, Davis GS. Deposition and translocation of inhaled silica in rats. Quantification of particle distribution, macrophage participation, and particle distribution, macrophage
function. Lab Invest 1982;47:533-42.

47 Warheit DB, Overby LH, George G, Brody AR Pulmonary macrophages are attracted to inhaled particles through complement activation. Exp Lung Res 1988;14:

48 Warheit DB, Hartsky MA. Role of alveolar macrophage chemotaxis and phagocytosis in pulmonary clearance responses to inhaled particles: comparisons among rodent species. Microsc Res Tech 1993;26:412-22.

49 Ferin J. Observations concerning alveolar dust clearance. Ann NY Acad Sci 1972;200:66-72.

50 Strom KA, Garg BD, Johnson JT, D'Arcy JB, Smiler KL. Inhaled particle retention in rats receiving low exposures of diesel exhaust. $\mathcal{F}$ Environ Health 1990;29:377-98. 